\title{
Gender and Age Analysis of Lung Cancer in Australia
}

Mochen Li and Raji Sundararajan*

School of Engineering Technology, Purdue University, West Lafayette, Indiana, 47906, USA

\begin{abstract}
Aim: To analyze the distribution and trends of incidence and death rates among males and females along with the period, using the historical lung cancer data of Australia. The purpose is that, with the analysis of the selected age-groups, it can generate some inspiration for lung cancer prevention, as an inch of prevention is better than a mile of treatment.

Background: Cancer has become the second leading cause of morbidity and mortality around the world following the heart disease. Among the top five common cancers listed by the WHO, lung cancer has been the always No. 1 cause of death among most countries. Although the lung cancer incidence rates in developed countries are relatively low (about 40 per 100,000 in average, among Australia, Canada, Denmark, England, Finland, France, and the United States), there are quite significant differences among different countries. It is of practical interest to study these in detail, and for that purpose, Australia, where in 2012, they smoked 21 Billion cigarettes, was chosen.

Result: Generally speaking, lung cancer incidence in Australia presented a decreasing trend in last few decades and it will keep stable for next few decades. From gender point, male incidence rate is keep decreasing slowly and female rate began to decrease after twenty-year increasing. Among all new diagnosed cases, 60 -year old people have an increased percentage than before.
\end{abstract}

Keywords: Lung cancer; Australia; Statistical analysis; Aged-adjusted group

\section{Introduction}

According to the data from GLOBOCAN 2012, there were about 1.8 million new lung cancer cases ( $12.9 \%$ of new all cancers) and 1.6 million deaths ( $19.4 \%$ of all cancer deaths worldwide) around the world in 2012 [1,2]. Lung cancer incidence rate and mortality rate in Australia (49.4 and 35.9 per 100,000) was smaller than that in more developed countries (about 66.7 and 53.7 per 100,000) [1]. Figure 1 shows the general situation of lung cancer in 11 more developed countries.

Cuurently, lung cancer has become the $5^{\text {th }}$ most common cancer (after Breast, Colorectal, Prostate and Melanoma) and $1^{\text {st }}$ leading cause of cancer death in Australia. In 2013, a total of 11,174 lung cancers were diagnosed in Australia. Meanwhile lung cancer causes more deaths than any other cancers, a total of 5,028 males and 3,204 females died from it [3]. In fact, lung cancer is the $4^{\text {th }}$ leading cause of death in Australia which is just following with Coronary heart disease, Dementia and Alzheimer disease and Cerebrovascular disease [3]. This paper provides an overview of statistics on lung cancer and its corresponding trend in the past three decades.

Key statistics of lung cancer in Australia in 2007 and 2017 are summed up firstly:

1) In 2007,9703 new cases were diagnosed which took about $9 \%$ of all cancer cases; and the estimated number in 2017 is about 12,400 which will be $9.3 \%$ of all cancer cases

2) In 2007, 7626 Australian people were killed by lung cancer which was about $19.1 \%$ of all cancer deaths; and in 2017 the estimated deaths of lung cancer are 9,000 which will be also about $19 \%$ of all cancer deaths

3) The percentage of 5 -year survival rate in 2007 is about $14 \%$; such value will increase to $16 \%$ in 2017

From the combined key statistics, the general status of lung cancer in Australia keeps a relatively stable trend. But, detailed analysis would present many different trends compared with general situation.

\section{Methods}

\section{Data analysis by gender}

In 1982, the general incidence rate of lung cancer was about 39.2 per 100,000 persons in Australia. But the incidence rates among males and females were quite different which was 61.9 vs $16.6[1,3]$. Since then, the incidence rates of all people have a continuous slow increase which from 39.2 to 48.3 in 2013. Compare with this small increase, trends of the incidence rates among males and females presented a very large difference: the incidence rates decreased from 61.9 in 1982 to 57.6 in 2013 for males; and that value of females increased from 16.6 in 1982 to 39.2 in 2013 [4,5]. Figure 2 shows trends of incidence rate and mortality rate with year increasing in all people, males and females separately.

From Figure 2, it can be concluded that the incidence rate of lung cancer increased about $136 \%$ in females; and decreased about $7 \%$ in males in 20 years. For mortality rate, such value increased $1.15 \%$ among males and increased 100\% among females. However, if taking account of the increase of population, incidence counts and mortality counts, all these results would have a little change. Table 1 shows the population, incidence counts and mortality counts in 1982 and 2013 in Australia $[4,6]$.

From 1982 to 2013, the female lung cancer cases increased 261\% and deaths increased 201\%; the male lung cancer cases increased $41 \%$ and deaths increased $18.9 \%$, and the population of Australia increased

*Corresponding author: Raji Sundararajan, School of Engineering Technology, Purdue University, West Lafayette, Indiana, 47906, USA, Tel: 765-494-6912; E-mail: li1049@purdue.edu

Received September 06, 2017; Accepted September 20, 2017; Published September 25, 2017

Citation: Li M, Sundararajan R (2017) Gender and Age Analysis of Lung Cancer in Australia. Gen Med (Los Angel) 5: 299. doi: 10.4172/2327-5146.1000299

Copyright: (c) $2017 \mathrm{Li} \mathrm{M}$, et al. This is an open-access article distributed under the terms of the Creative Commons Attribution License, which permits unrestricted use, distribution, and reproduction in any medium, provided the original author and source are credited. 
Citation: Li M, Sundararajan R (2017) Gender and Age Analysis of Lung Cancer in Australia. Gen Med (Los Angel) 5: 299. doi: 10.4172/23275146.1000299

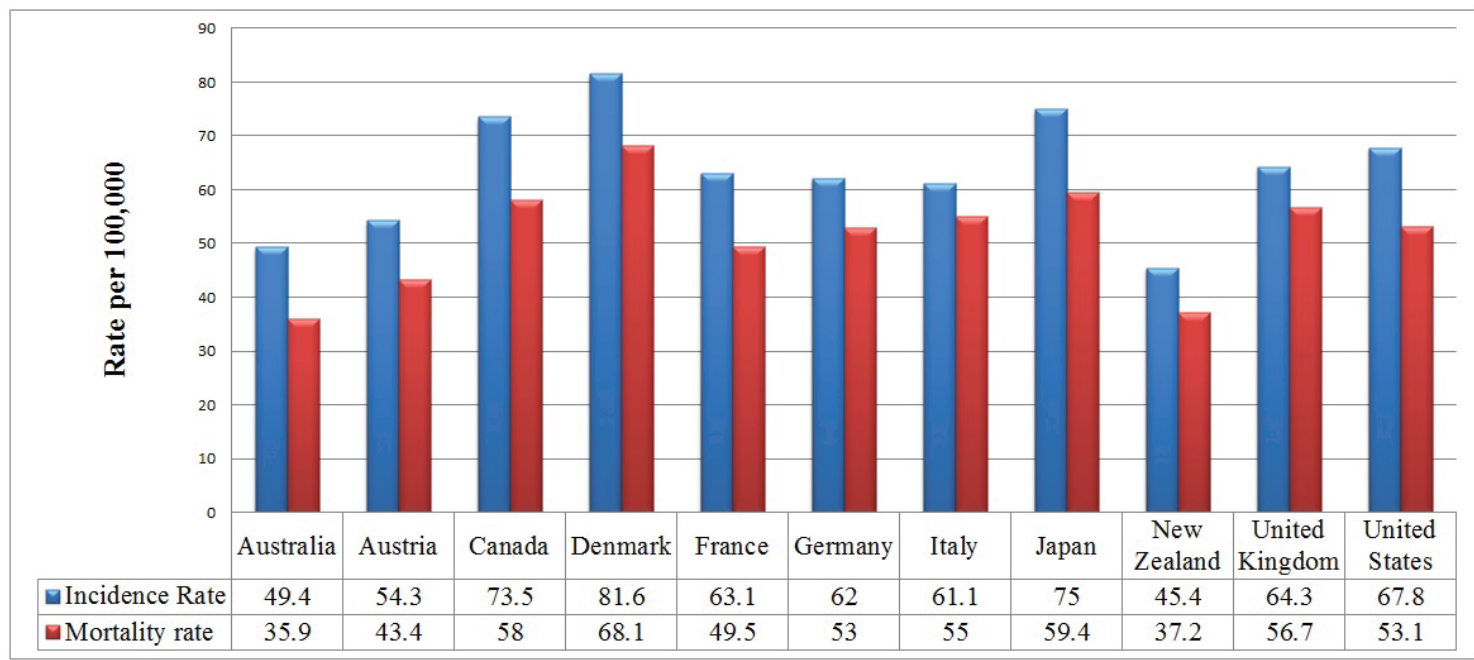

Figure 1: Lung Cancer General Situation in 2012 among More Developed Countries [1].
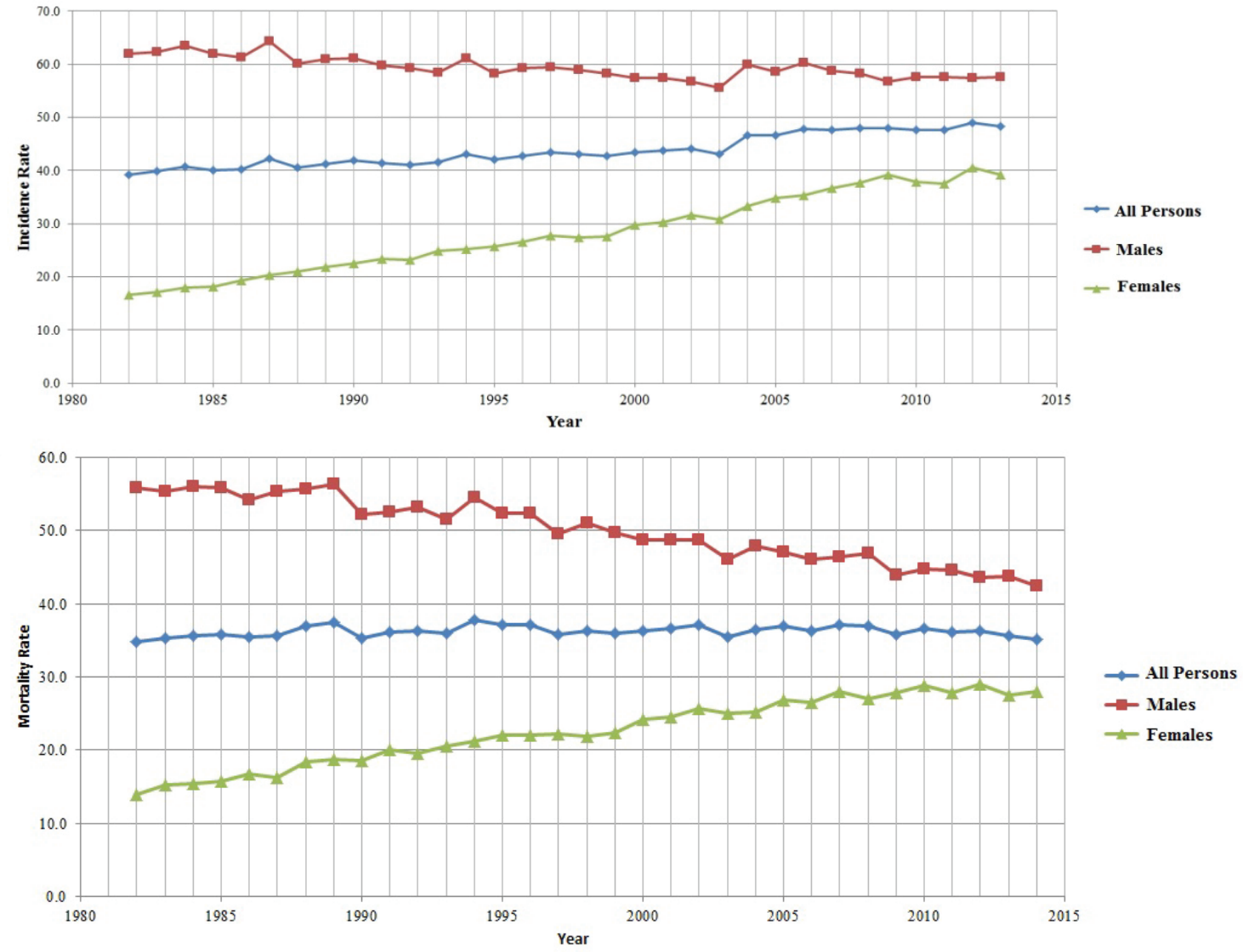

Figure 2: Trends of Incidence Rate and Mortality Rate (per 100,000) in Australia from 1982 to 2013.

$52 \%$. Due to the population increase among males and females was nearly equal, the male incidence rate decreased about $7.3 \%$ and the mortality rate $22.7 \%$; the female incidence rates increased about $71.2 \%$ and mortality rate increased 32\% of those in 1982 .
From the comparison of lung cancer incidences and deaths in four periods $(1982,1992,2002$, and 2013) in Australia it can be noticed that there is a significant increase in female percentage of them. Especially, the percentage of female incidence cases and mortality counts both had 
Citation: Li M, Sundararajan R (2017) Gender and Age Analysis of Lung Cancer in Australia. Gen Med (Los Angel) 5: 299. doi: 10.4172/23275146.1000299

Page 3 of 7

\begin{tabular}{|l|l|l|l|l|l|}
\hline Year & Population & $\begin{array}{l}\text { Incidence } \\
\text { Counts in } \\
\text { Males }\end{array}$ & $\begin{array}{l}\text { Incidence } \\
\text { Counts in } \\
\text { Females }\end{array}$ & $\begin{array}{l}\text { Mortality } \\
\text { Counts in } \\
\text { Males }\end{array}$ & $\begin{array}{l}\text { Mortality } \\
\text { Counts in } \\
\text { Females }\end{array}$ \\
\hline 1982 & $1,51,78,000$ & 4,691 & 1,260 & 4,227 & 1,061 \\
\hline 2013 & $2,31,17,353$ & 6,627 & 4,548 & 5,028 & 3,204 \\
\hline
\end{tabular}

an obvious increase from $21 \%$ and $20 \%$ in 1982 to $41 \%$ and $39 \%$ in 2013.

Figure 3 shows the change of percentage of incidence cases and mortality counts among males and females in Australia in those four years. An interesting phenomenon was: even death will occurred after

Table 1: Population and incidence counts of lung cancer in Australia. few years diagnosed as lung cancer, the percentage distributions of

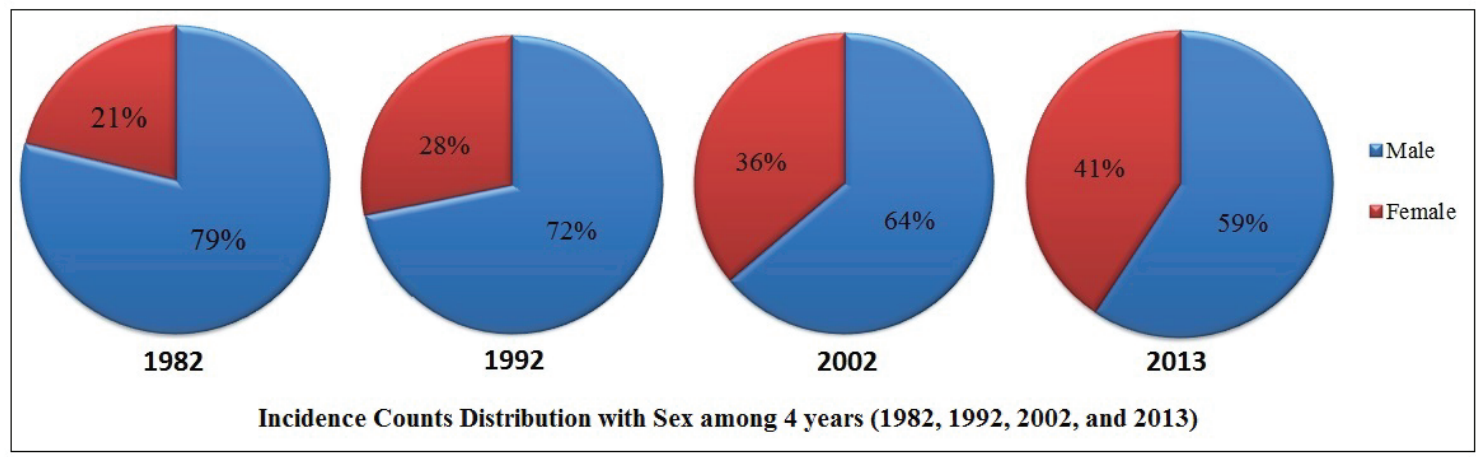

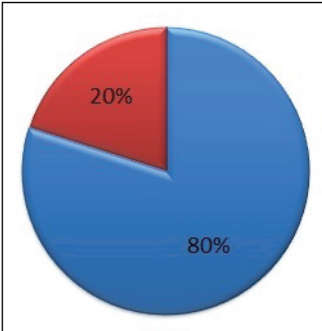

1982

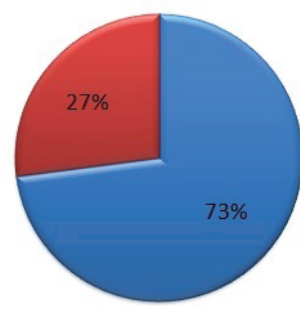

1992

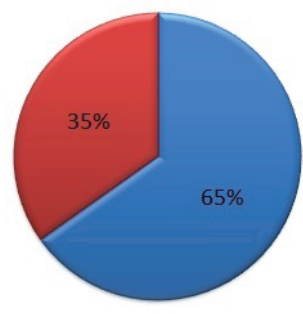

2002

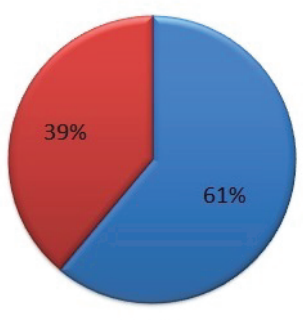

2013

Mortality Counts Distribution with Sex among 4 years $(1982,1992,2002$, and 2013)

Figure 3: Male and female percentage of lung cancer incidence cases and mortality counts in Australia.

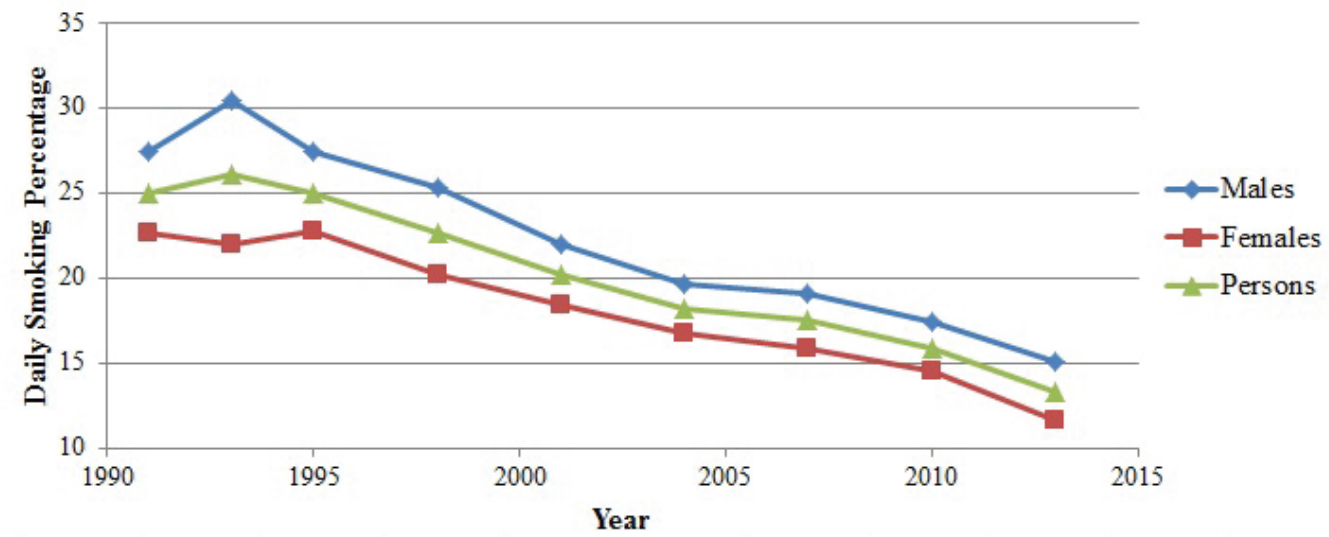

\begin{tabular}{|l||r||r|r|r|r|r|r|r|r|r|}
\hline Sex & 1991 & 1993 & 1995 & 1998 & 2001 & 2004 & 2007 & 2010 & 2013 \\
\hline \hline Males & 27.5 & $\mathbf{3 0 . 4}$ & 27.4 & 25.3 & 22 & 19.6 & 19.1 & 17.4 & 15.1 \\
\hline \hline Females & $\mathbf{2 2 . 6}$ & $\mathbf{2 2}$ & $\mathbf{2 2 . 8}$ & $\mathbf{2 0 . 2}$ & $\mathbf{1 8 . 4}$ & 16.7 & 15.9 & 14.5 & 11.6 \\
\hline Persons & $\mathbf{2 5}$ & $\mathbf{2 6 . 1}$ & $\mathbf{2 5}$ & $\mathbf{2 2 . 7}$ & $\mathbf{2 0 . 2}$ & $\mathbf{1 8 . 2}$ & 17.5 & 15.9 & 13.3 \\
\hline
\end{tabular}

Figure 4: Tobacco smoking trend in Australia. 
incidence counts and mortality counts among males and females were almost same in these four years.

The different pattern of incidence rates in males and females reflect the historical differences in smoking. Figure 4 presents the tobacco smoking trends in Australia from 1991 to 2013. Although smoking rates in females decrease since 1980 among developed countries, smoking among women is still common in many countries. In 2007, about $17 \%$ Australians aged 14 years and over are reported smoking daily [7]. In fact, the male smoking rate has kept declining since 1950s which reduced from $72 \%$ in 1945 to $18 \%$ in 2007 . For women, this rate increased slightly between 1940s and 1980s from 26\% in 1945 to $35 \%$ in 1980 and then it followed by a decline from $31 \%$ in 1980 to $15 \%$ in 2007 [7].

Based on the report from Australian government, smoking is the primary single cause of lung cancer among both males and females, responsible for $90 \%$ and $65 \%$ of new cases separately. Historically speaking, female smokers had a lower risk of developing lung cancer than males. However, those female smokers would have a higher relative risk of lung cancer with time, for developing the lung cancer [8]. It is argued that the possible reasons could be the difference in the number of cigarettes per day, different smoking ways and different types of cigarettes smoked [8-10].

Considering that the female incidence rate presented a continuous increase from 1982 to 2009 (Figure 2), it began to show a slightly decrease status of new cases after 2010. Through the comparison between American female lung cancer incidence trend and American female smoking prevalence, it is noticed that the effect of smoking will appeared in lung cancer after 2 or 3 decades lag [11]. Besides, the female lung incidence trend in Australia also matches this result: from 1991 the daily smoking percentage among women had decreased from 22.6 to 11.6 [7]. Additionally, a US study also concluded that there is no statistically significant difference of incidence rates between males and females for who smoked more than two packs daily and a significant difference between genders for those who never smoked. Generally speaking, a woman who never smoked would have a 30\% higher risk of lung cancer than a man [12].

In order to get an initiatory analysis of trend in the upcoming years, two prediction of lung cancer by gender were estimated from the simple linear regression (SLR) estimation. Figure 5 shows these trends. Based on the SLR model, lung cancer incidence rate and mortality rate among women will get more and more close to that among men in next few years.

\section{Data analysis by age, period and cohort}

Even though the amounts of incidence cases are very different among more developed countries, the aged-distributions of incidence cases were quite similar. From the comparison of aged-group among more developed countries, the aged-distributions of lung cancer are very similar: more than half new cases are diagnosed in people over 70 years old, about $40 \%$ cases come from group of age between 50 and 69 , and less $5 \%$ new cases are younger people (age less than 50 ) $[1,4,5]$.

Figure 6 shows the aged-distribution of incidence cases in Australia from 1982 to 2013. As we know, the risk of having lung cancer will increase with age. From the view of incidence percentage of higher age, new patients of age between 60 to 79 continued decreasing since 1992 (from 69\% in 1992 to $60 \%$ in 2013), incidence cases of over-80-year presented an increase trend in recent 3 decades (from $8 \%$ in 1982 to $24 \%$ in 2013) and correspondingly people of age between 40 to 59 have
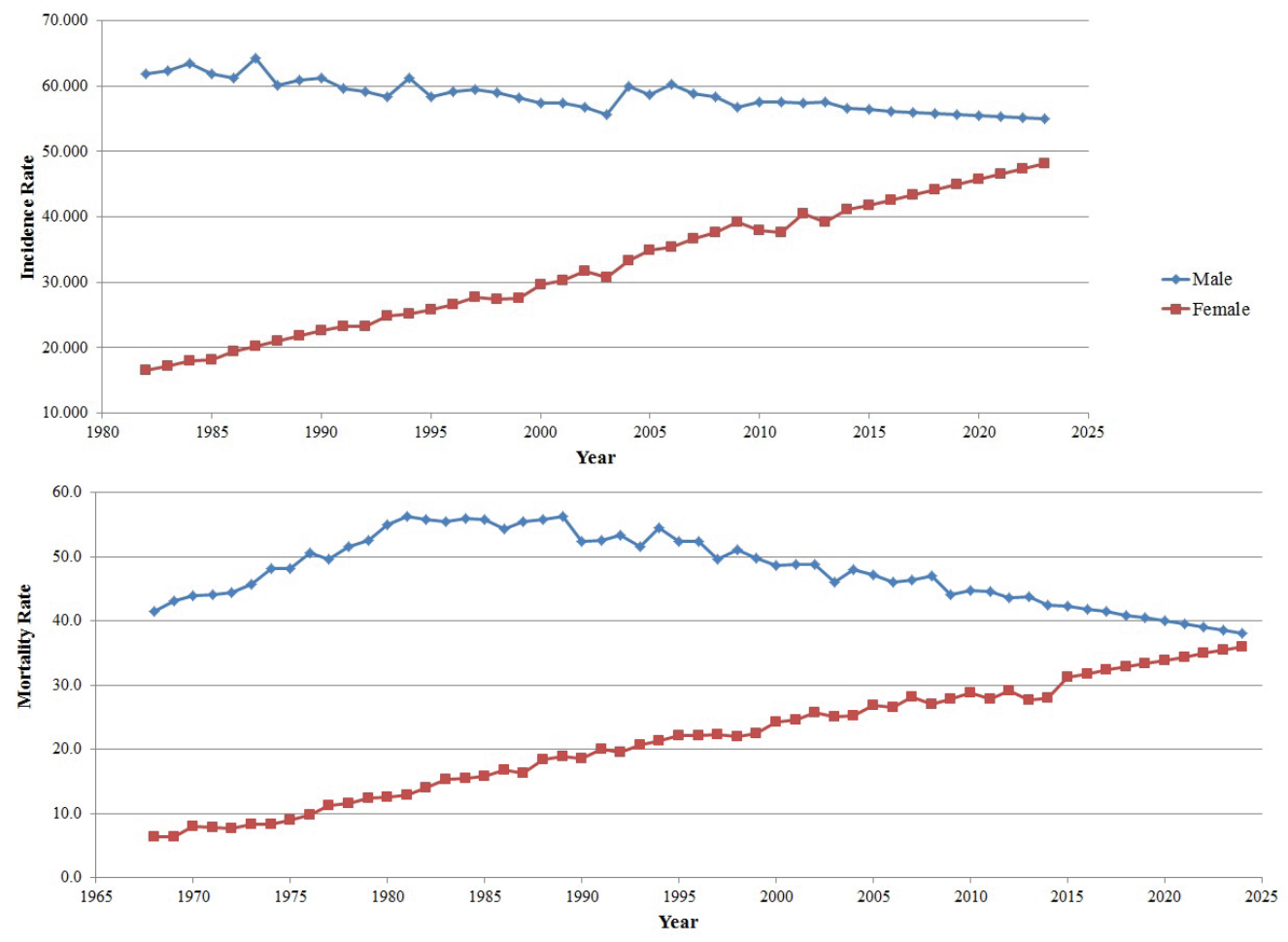

Figure 5: Estimation of lung cancer trend in Australia by gender. 
Citation: Li M, Sundararajan R (2017) Gender and Age Analysis of Lung Cancer in Australia. Gen Med (Los Angel) 5: 299. doi: 10.4172/23275146.1000299

Page 5 of 7

less new lung cancer cases percentage (from 25\% in 1982 to $15 \%$ in 2013).

In fact, the total new cases of age-group, between 40 to 59 actually increased in three decades (1,465 in 1982 vs. 1,725 in 2013). But compared with the increase of all aged-groups (5,951 in 1982 vs. 11,174 in 2013), this group decreased with the population increase. Compared with other developed countries, percentage distribution of aged-groups and their trends also have similar results. Figure 7 shows that the percentage of over-60-year old lung cancer cases has a huge increase in Australia from 1982 to 1998 (74.5\% in 1982 vs 82.4\% in 1998). From 1999 , such value presents a parallel trend with that in the U.S. However, over-60-year old people in Australia have a 2\% higher risk of lung cancer than people in the U.S $[1,13,14]$.

In order to analyze if the effect of age and birth cohort for the lung

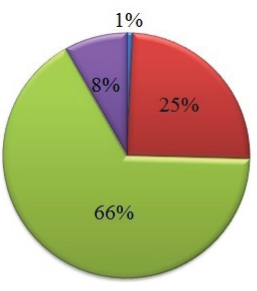

1982

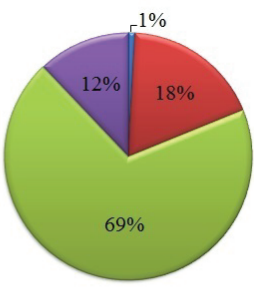

1992

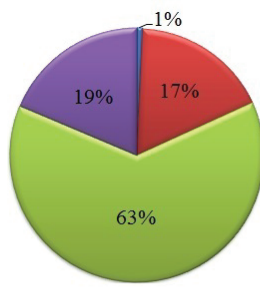

2002

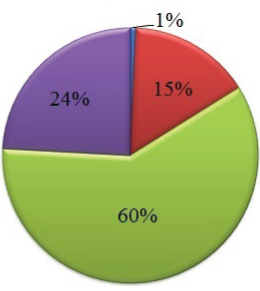

2013 $\square<40$

प $40-59$

$\square 60-79$

$\square>80$

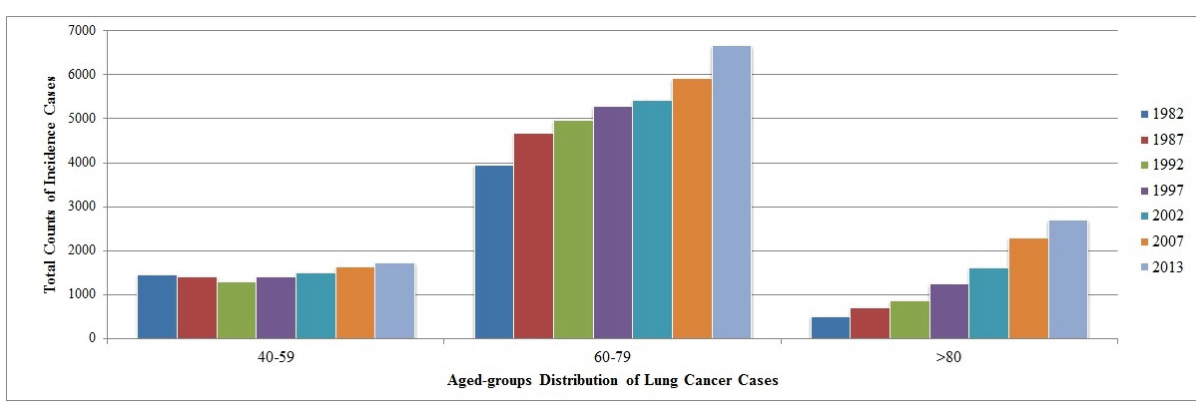

Figure 6: Age distribution of lung cancer incidence cases in Australia.

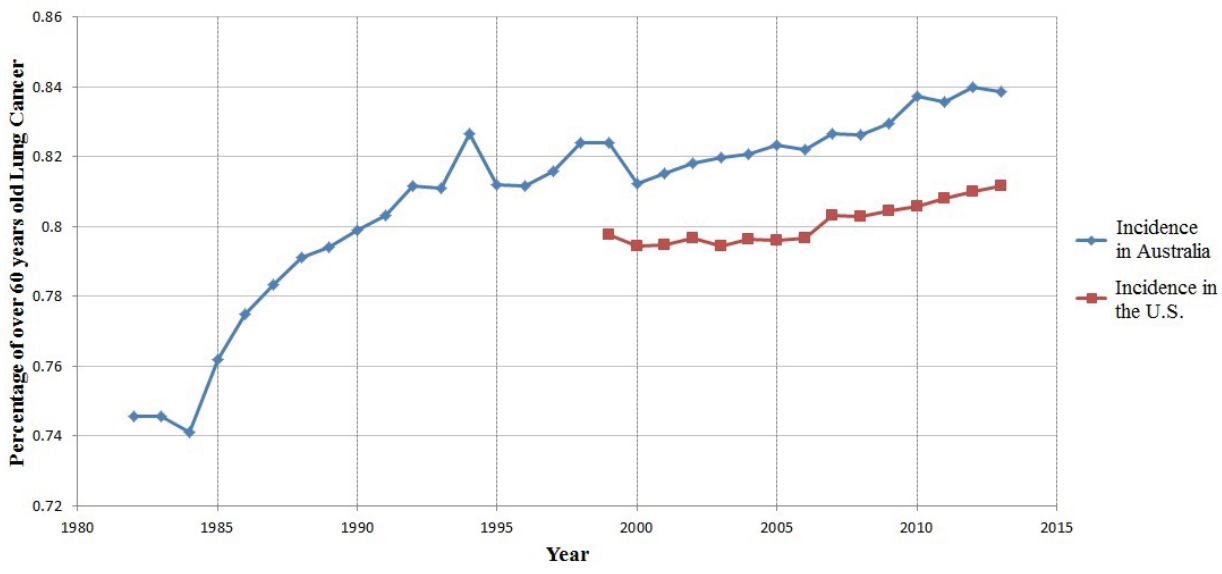

Figure 7: Over 60 year old people lung cancer trend.

\begin{tabular}{|c|c|c|c|c|c|}
\hline Group A (Birth in1943 - 1947 ) & & Group B (Birth in 1948-1952 ) & & Group C (Birth in 1953-1957) & \\
\hline 1982(Age 35-39) & 2.9 & 1987(Age 35-39) & 3.7 & 1992(Age 35-39) & 2.7 \\
\hline 1987(Age 40-44) & 9.7 & 1992(Age 40-44) & 6.4 & 1997(Age 40-44) & 7.3 \\
\hline 1992(Age 45-49) & 19.9 & 1997(Age 45-49) & 18.7 & 2002(Age 45-49) & 16.3 \\
\hline 1997(Age 50-54) & 37.7 & 2002(Age 50-54) & 32.8 & 2007(Age 50-54) & 33.1 \\
\hline 2002(Age 55-59) & 68.7 & 2007(Age 55-59) & 62.5 & 2012(Age 55-59) & 61 \\
\hline 2007(Age 60-64) & 109.1 & 2012(Age 60-64) & 107.8 & - & - \\
\hline 2012(Age 65-69) & 176.3 & - & - & - & -- \\
\hline
\end{tabular}

Table 2: Selected data of age-group in different period. 
Citation: Li M, Sundararajan R (2017) Gender and Age Analysis of Lung Cancer in Australia. Gen Med (Los Angel) 5: 299. doi: 10.4172/23275146.1000299

Page 6 of 7

cancer would change with period increasing, 3 aged-specific incidence rates were tracked from 1982 to 2013 by 5-year birth cohorts [16]. Because there were few lung cancer patients younger than 30 years, the cohort analysis focus on incidence groups aged over 35 years. The incidence data were arranged with 8 five-year age groups (35-39, 40-44,
45-49, 50-54, 55-59, 60-64, and 65-69), 7 five-year periods (1982, 1987, 1992, 1997, 2002, 2007, and 2012), and 3 birth cohorts (1943-1947, 1948-1952, and 1953-1957). Table 2 shows the collected data. Figure 8 shows the trends of lung cancer incidence rates with age increasing in different periods [15].

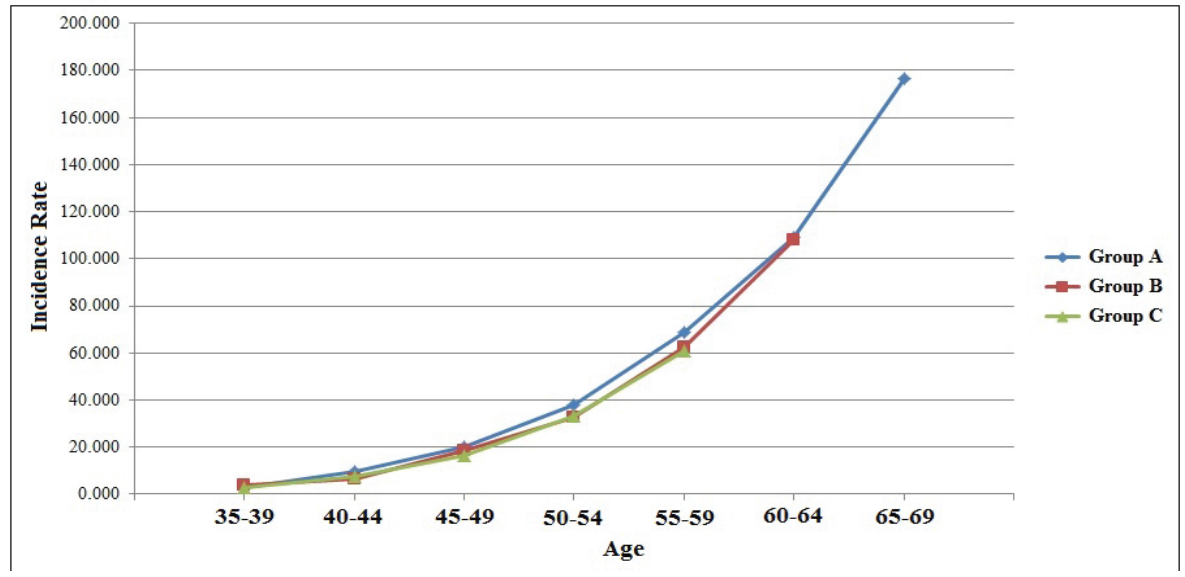

Figure 8: Age-specific incidence rates per 100,000 according to 5-year period.
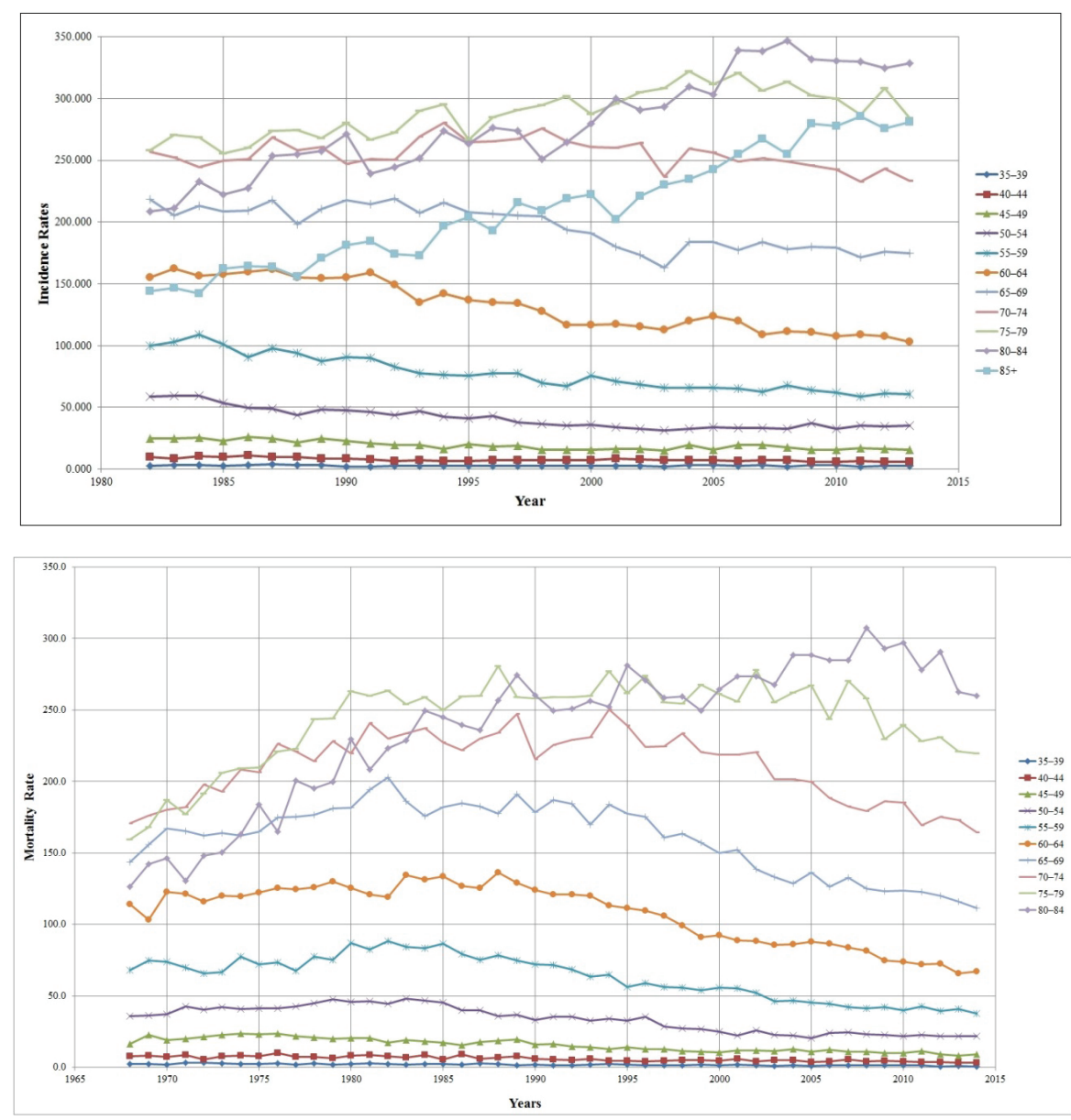

Figure 9: Trends of lung cancer incidence rate and mortality rate in Australia. 
Trends of these three selected groups in Figure 8 shows that lung cancer incidence rates almost have the same increasing rates with increase in age, even in different period. On the other hand, based on this trend of the selected group, with increase in time, it shows that a person over 60 years old would have 38 times higher than his age of 35 years in the possibility of risk of getting lung cancer. Figure 9 shows trends of lung cancer incidence rates and mortality rates among all aged groups from 1982 to 2013.

It can found that all aged group younger than 70-year have a downward trend since 1995, over 80-year groups continue increasing with age and 70-74 year group present a stable trend. As the effects of cohort and period are quite stable which means the increase rate of incidence counts for different period should be similar, therefore from the increase of incidence rate among over-75-year old people, it can be concluded that people in Australia have longer life expectancy than before.

For mortality rates, from the 1990s, most aged groups showed a decrease trend along with time. Meanwhile, from 1970s to 1990s, the mortality rate among the top three old aged groups (70-74, 75-79, 80-84) presented a continuous increase and then those rates began to decrease. Combined trends of incidence rate and mortality rates, it can concluded that the survival rate of lung cancer has been improved. However, even though such conclusion can be supported by data from Australian Institute of Health and Welfare (AIHW), that is, the 5-year relative survival increased from $8 \%$ to $11 \%$ among males and $10 \%$ to $15 \%$ among females; lung cancer survival still remains very low [4].

\section{Conclusion}

This study provides a general analysis of lung cancer incidence rates and counts in Australia. From the perspective of gender and age, it is can draw the following results:

1) Lung cancer incidence of males has a continuous slight decline from 1982 to 2013; but at the same time, the female incidence rates was keeping increasing in Australia. The reduction in male incidence could be attributed to the sustained, concerted and comprehensive public policy efforts from all levels of government and action from public health organisations, since 1973. These include: health warnings mandated on all cigarette packs, bans on all cigarette advertising on radio and television, phased in bans on smoking in workplaces and public places, bans on advertising of tobacco products in newspapers and magazines published, increase in the tobacco excise, introduction of tobacco plain packaging, and updated and expanded graphic health warnings.
2) Currently, lung cancer is still the leading cause of death from cancer for people in Australia.

3) Besides the known risk factor-smoking, the effect of age is almost the same no matter what age group it is.

4) No matter which country, people over 60 years old should be given a regular check-up for the prevention of lung cancer.

5) Given the effect of period and cohort, in more developed countries the status of lung cancer is relatively stable.

Considering that there are almost 3 million smokers in Australia and they have smoked 21 Billion cigarettes, the prevention is more a societal/life style issue. With the free and abundant availability of cigarettes (tobacco), the most well known carcinogen for over several decades, at affordable prices and the accompanied economics and income to the governments, the prevention of smoking could be a rather challenging task [16].

\section{References}

1. GLOBOCAN 2012

2. World Cancer Research Fund International, Lung Cancer Statistics.

3. Australia Institute of Health and Welfare (AlHW) "Caner in Australia 2017".

4. Australian Institute of Health and Welfare (AIHW).

5. Cancer Australia.

6. The World Bank.

7. Tobacco in Australia.

8. Thun MJ, Heath CW Jr. (1997) Changes in mortality from smoking in two American Cancer Society prospective studies since 1959. Prev Med 26: 422426.

9. Morabia A, Costanza MC, Bernstein MS, Rielle JC (2002) Ages at initiation of cigarette smoking and quit attempts among women: a generation effect. Am J Public Health 92: 71-74.

10. Hoffmann D, Hoffmann I (1997) The changing cigarette, 1950-1995. J Toxicol Environ Health 50: 307-364.

11. The Tobacco Atlas, Smoking-Among-Women.

12. Freedman ND, Leitzmann MF, Hollenbeck AR, Schatkin A, Anet CC (2002) Cigarette smoking and the subsequent risk of lung carcinoma in the men and women of a large prospective Cohort study. Lancet Oncol 99: 245-251.

13. Siegel RL, Miller KD, Jemal A (2016) Cancer statistics, 2016. CA Cancer J Clin 66.

14. The State of Cancer Control in Australia.

15. van der Hoff NM (1979) Cohort analysis of lung cancer in The Netherlands. Int J Epidemiol 8: 41-47.

16. Tsugawa Y, Hashimoto K, Tabuchi T, Shibuya K (2017) What can Japan learn from tobacco control in the UK? Lancet 390: 933-934. 